\title{
Toward a theory of international politics: \\ Quincy Wright's Study of international relations and some recent developments ${ }^{1}$
}

\section{MORTON A. KAPLAN}

\section{University of Chicago}

With the publication of The Study of International Relations (10) Professor Quincy Wright has brought to a climax a distinquished academic career which established him as the foremost theorist of international relations in the United States. This book provides a definitive statement of the essence of his theoretical contributions and carries out the design already elaborated in The Study of War (11). Professor Wright's great reputation and the range of his influence can easily be explained. At a time when other writers were concerned with diplomatic history alone, or international law alone, or ideological determinants of power alone, Wright was attempting to integrate all the factors which could be used to explain international behavior. Among the root disciplines of international relations Wright includes international law, diplomatic history, military science, international politics, international organization, international trade, colonial government, the conduct of foreign relations, world his-

1 I should like to thank John R. Platt, of the Department of Physics, and David Apter and Martin Diamond, of the Department of Political Science, at the University of Chicago, for helpful comments. This paper was completed at the Center of International Studies, Princeton University, and I wish to thank the Center for its assistance. tory, world geography, the psychology and sociology of international relations, humanistic and biological disciplines, regional studies, operational research, and group dynamics.

To achieve the scope necessary for his undertaking, Wright has drawn on all branches of the social sciences. He-together with Lasswell $(4,5)$-has attempted systematically to explain national policy in terms of such factors as group structure and interests, personalities of decision-makers, sociological characteristics of state organization, and technological level. He has pioneered especially in relating state capabilities (such as technological advancement, resource abundance, energy, strength, flexibility) and national value orientations (such as objectivity, abstractness, liberality) to other national characteristics (such as specialization, high tension, security, reliability, defensiveness, rationality, tolerance, democracy, individualism, optimism, and tranquillity). In turn, he has related these factors to progress in civilization and to national aggressiveness.

As the examples just cited indicate, Wright's action field essentially constitutes a factor model in which every nation occupies a position on each of a number of dimensions. The behavior of the nation is a 
product of the complex interaction of the tendencies represented by the positional mappings. Thus, if a nation is rigid and high on energy, it tends to have high tension. Wright would place the U.S.S.R. in this category. If a nation is flexible and energetic, it tends to develop specialized skills. The United States fits in this category. If a nation is lethargic and flexible, it tends toward a state of low tension. Wright places Switzerland here. If a nation is lethargic and rigid, skills tend to be specialized. Wright placed the old China here. If a nation is high on specialization and tension and low on security, satisfaction, defensiveness, rationality, tolerance, democracy, individualism, and so forth, it tends to be aggressive or warlike. If a nation is high on specialization, tension, reliability, rationality, tolerance, democracy, and so forth. it tends to further the progress of civilization. (Wright's action fields may also be applied to individuals.)

This approach certainly has its merits in stimulating an investigation of variables relevant to international behavior. However, the question arises whether a largely mechanical or static factor model of the type used by Wright is adequate for describing or predicting international behavior. In reading Wright's book, one has no sense of an ongoing international system with describable internal processes and distinctive role occupants. The theory leaps from the predisposition to behavior or the motivating factors to the final decisions or actions without any consideration of the matrix, whether social or strategic, which makes some patterns of behavior stable and others unstable or which makes one pattern rational and another irrational. In short, the theory largely ignores the dynamics of international politics, without which it seems impossible to account adequately for the behavior of nations.
It would be wrong to say that Professor Wright attempted the less important task or even that the direction in which he started has no further validity. The study of international politics can no more do without Wright's contributions than can his approach exhaust the theoretical treatment of international politics. Both a factor approach and a dynamic approach are necessary for achieving a complete theory of international relations.

In this paper an attempt will be made to understand the general requirements of a theory of international relations, to map out the theoretical relationship between the factor approach and the theory of international politics, and to determine the directions in which the field should be moving.

\section{Requirements of a Systems Theory of International Politics}

Just as a theory of economics must describe and predict behavior in a distinct type of economic system-for example, perfectly competitive or imperfectly competitive-or as a sociological theory of marriage must describe types of family systems and the conditions under which they can be maintained, so a theory of international politics must be able to describe distinctive kinds of international systems and the conditions under which they are maintained. Warlike and peaceful behavior are important types of international behavior, but a theory of international politics must begin with the macroscopic system of action within which these activities occur and which acts as a matrix for the activity. If we did not proceed in this fashion, we would be proceeding as if international politics, unlike every other kind of social activity, had no proper system structure of its own.

If one agrees thus far, one will next attempt to develop a model or models of the international system as a distinctive kind of 
social system. Two tools for the construction of such a model are the steady-state equilibrium and the theory of strategy. Other theoretical problems, such as the number of variables in a theory, the degree of abstractness of a theory, and the differences between theory construction and engineering applications of theory, will also prove important. But a discussion of these problems will be deferred until after the discussion of the systems theory of international politics because they provide the link between that kind of theory and Professor Wright's work.

\section{THE STEADY-STATE MODEL}

There are basically two kinds of equilibrium models-the mechanical and the steady state. The mechanical equilibrium model states that for every force there is a counterforce; forces thus tend to equalize each other. In the steady-state model, specified variables remain unchanged (within given limits), despite external disturbances, as a consequence of changes in still other variables of the model. To choose an example, the temperature of the blood is maintained in hot weather by the processes which produce perspiration and in cold weather by those that produce goose pimples. In most systems with a steady state there must be a structure that persists over time. Except as part of a biological system, the rise in the temperature of the blood would not trigger the processes that produce perspiration. A thermostat also maintains a steady state of heat in the system within which it operates. Again there is a definitely structured system within which the thermostat functions. This system can be described, and an explanation of its functioning can be offered. ${ }^{2}$

2 The steady state does not "disobey" any of the laws of mechanical equilibrium. If one thinks of a system in which a watchman sets
The concept of the steady state leads the construction of a theory of international politics in a given direction. It directs attention to the mechanisms of the international social system that maintain or undermine steady states. It also leads to a search

pumps in operation whenever a vessel begins to fill with water, the inputs of energy from the pumps are equal to the outputs in terms of the evacuation of water from the vessel. But the same mechanical equilibrium model that describes the operations of the physical system is not adequate to the description of the social system. There is no correspondence in terms of energy between the orders given to the watchman by his employer and the action of the pumps. Nor, if one thinks of the Russian troops in Hungary in 1956, is there any mechanical equilibrium between the orders given to the troops and the social result, that is, the maintenance of Communist rule, although the mechanical laws continue to hold. When one employs the concept of mechanical equilibrium or balance and when one employs the concept of the steady state, two different kinds of systems or frames of reference are employed. The concept of a balance when applied to mechanical equilibrium conveys information meaningfully. For example, two weights which depress a spring scale identically will, if placed in the cups of a symmetric "balance," lie in a plane parallel to the surface of the earth. If the cups are parallel to the earth and the weights are not equal, one can infer that the "balance" is not symmetric. If the "balance" is symmetric and the cups are not parallel to the earth's surface, one can predict that the weights will not depress a spring scale equally. The assertion that the thermostat is in balance with the temperature of the room or the operation of the furnace does not have similar meaning. Nor can social equilibria ordinarily be called "balances" meaningfully because the concept does not convey additional information as when it is used for mechanical systems. In steady-state phenomena the problem cannot be resolved by the application of a phrase like "balance," which obscures rather than illuminates. The problem is rather to find the conditions which maintain or disrupt the steady state in a given system and to find the mechanisms which explain these relationships. 
for steady states in the international system. If one discovers what is steady, under what conditions it is steady, and under what conditions it is not, a description of the system is at hand, and a theory of the system may be constructed.

\section{THE THEORY OF STRATEGY}

The theory of strategy is developed in both statistical and game theory. Its most interesting development stems from the game theoretic work of von Neumann and, in particular, The Theory of Games and Economic Behavior by von Neumann and Morgenstern (9). An interesting guide to the subject is contained in Luce and Raiffa (7). The theory of strategy is a theory that, in principle, permits a player to select a line of play in a given situation that is in some sense rationally optimal. Game theory is really too complicated-and too little explored-to be applied in a detailed way to real situations as they are met by real players. The theory, however, illuminates the nature of certain kinds of games and permits mathematical treatment of the theory which underlies the games. These games do give us insight into the nature of some real situations.

Game theory also employs the concept of equilibrium, although it employs the concept in a special way. Strategies are in equilibrium when the players will not rationally move from them. For instance, it is possible that disarmament is an optimal payoff for both the United States and the Soviet Union but that the nature of the strategic matrix is such that the arms race, once started, represents an equilibrium from which neither player will move rationally unless somehow the structure of the game is changed.

Individuals and organizations, such as the nation-state, have some degree of freedom in the sense that they are free to choose from among several alternative courses of action. Thus the future is not simply a mechanically determined projection of the past. The theory of games, which emphasizes this rational component, has a more important place in international politics than in most other areas of social or political theory. Although some social processes, like the spread of rumors, seem to be determined more by certain kinds of constraints on communication flows than by rational decisions and although some kinds of large-scale phenomena like the rate of suicide seem to obey almost mechanical laws, international activity appears to have a large rational component. This may stem partly from the small number of important nation-states in the international system and partly from the insulating mechanisms within national political systems that emphasize the rational component in decision-making.

Thus the theory of games, which is a theory of rational choice, is suitably adapted to a theory of international politics. One may also note the ease with which the sociological and game concepts can be translated into each other. The sociological "role" can be translated as the game theoretic "strategy," and the sociological "actor" can be translated as the game theoretic "player." The social system "steady state" can be mapped into the game theoretic "strategic equilibrium."

\section{SYSTEMS THEORY OF INTERNATIONAL POLITICS}

The term "systems theory" may be misleading if it seems to imply the existence of a general theory from which theories of specific subject matters may be deduced. As used by Ashby, in his brilliant work on brain analogues (1), the term "system" simply refers to a set of variables and their relationships, if any. Variables that are not related in any way, however, would con- 
stitute a most uninteresting system. Therefore, systems which are the subject of study are composed of variables that are related. From this vantage, there is nothing presently extraordinary about the concept of "system," although many proponents of general systems theory do hope to discover general formulations. Yet, as a heuristic device, the concept is quite powerful, for it turns attention to systems of action rather than to isolated relationships or variables; it turns attention to the framework of action rather than to the discrete actions; and it turns attention to potential analogues from other disciplines.

In the brief period in which the term "systems theory" has been employed, its use to build models in social science has been relatively slight. The important work of Parsons (7) and Levy (6) deserves notice. In the field of international politics, the very important work of Arthur Lee Burns, of Australia, should be mentioned (2); however, this work, although fairly rigorous, cannot be adapted to comparative analysis without some effort. An application of systems theory to international politics is made in System and Process in International Politics (3) - a work which came out almost simultaneously with that of Burns. This work may be regarded as an initial effort, however, rather than as a final integrated theory, for the adaptation of the game theoretic elements to the steady-state elements is not rigorous and may possibly be unsatisfactory.

The systems theory of international politics uses both steady-state analysis and strategic theory. The variables employed in the theory consist of classificatory variables which name actors, like "nation-state" or "national actor," or which represent social relationships, such as "bloc member" or "leading bloc member"; essential rules, like "increase capabilities" or "form a counter- alliance," which constitute the characteristic behavior of the system, that is, which describe the behavior that is in strategic equilibrium; transformation rules that specify the conditions under which a steady state will be transformed rather than maintained; information variables that indicate the information the actor has when making its decisions; and capability variables that indicate the means the actor has to influence given ranges of behavior. These variables involve both steady-state and strategic analysis. The steady-state analysis follows from the fact that the states of some variables remain within given limits as a consequence of changes in other variables. Strategic analysis is involved because the essential rules specify the moves or actions necessary to maintain national values under given conditions of the other variables of the system.

Models of at least six different international systems-the "balance-of-power" system, the loose bipolar system, the tight bipolar system, the universal system, the hierarchical system, and the unit veto system-can be constructed. Only the first two will be described here and these only briefly. ${ }^{3}$ This brief treatment, however, should suffice to indicate the nature of the theory and of the mechanisms which maintain the steady states in a way susceptible to strategic analysis.

The term "balance of power" is employed within quotes for reasons explained in an earlier section-primarily because the system is not one of mechanical equilibrium. This "balance-of-power" international system is one in which there is no political subsystem of the international system itself. All actors in this system are of the national actor classification. There must be at least five national actors who have major capabilities, that is, who must be very strong,

${ }^{3}$ For fuller treatment see Kaplan (3). 
and whose capabilities are in some sense in the same general range. The essential rules of the system call for the major national actors to increase their capabilities; to go to war, if necessary, for this purpose; to stop fighting rather than to eliminate another major national actor from the system; to oppose any coalition or single actor that threatens to become predominant within the system; to constrain actors who subscribe to supranational organizational principles; to permit defeated major actors to re-enter the system; and to treat all major actors as equally acceptable role partners.

The rules can be explained simply, if not with complete satisfaction, from a strategic point of view. If one assumes that the primary objective of national policy is to maintain the independent existence of the nation as the kind of society it is, the essential rules may be viewed as describing the pattern of activity which is necessary to accomplish this end under the conditions specified for the other variables and for given parameter values of the international system. For instance, the fact that the international system does not have an independent political subsystem of its own places the primary responsibility for national security upon the nation. Despite the existence of other values toward which national policy may be oriented, in an uncertain and dynamic world, this responsibility for its security will motivate the nation to search for new sources of capabilities. One way to do this is to enter into an alliance. If one alliance is formed, other nations will be motivated to form a counteralliance to protect their interests. If a coalition becomes predominant, it will tend to lose some of its members either because the outside coalition can offer more or because, if victorious, it would become a threat to some of its own members. If a single nation approaches predominance, it becomes a threat to all other nations, and they would rationally be motivated to oppose it.

The aims of war are limited in the "balance-of-power" system in order to maintain the number of major national actors. This is a protective device. If, for instance, the number of major actors were reduced to three-in the absence of nuclear weaponsa victorious coalition of two nations might eliminate the third before the weaker of the victors could ally itself with the defeated nation to prevent this. This system would be unstable because it would put a premium on striking first, upon entering the first coalition, and then on becoming predominant. This system of three nations would be characterized by extreme suspicion and distrust. When there are at least five major national actors to begin with, the potentialities for counteralliance are greater. With at least five major nations, limiting the aims of war serves the function of multiplying the number of potential coalitions that can be formed to protect one's security. Restoring defeated actors to the system and treating all major actors as acceptable role or alliance partners have the same function. These rules also help to explain the observance of "gentlemen's rules" concerning declarations of war and treatment of prisoners. If the enemy of today is the potential ally of tomorrow, normative rules must be employed that minimize suspicion and strain and that facilitate the exploitation of all existing possibilities for alliance. For the same reasons, alignments in the "balance-of-power" system will tend to be instrumental and fragile. The more rigid the alignments, that is, the lower the probability of realignment to oppose predominance, the less the security. Therefore, alignments will be formed and re-formed on the basis of short-term instrumental interests. Thus within the system any nation may play the role of "balancer" by swinging to the weaker of two coalitions. 
For logistic reasons this role was most convenient to Britain in the nineteenth century; but, in principle, any nation might have played the role of "balancer." There is no role differentiation in this system.

Thus the systems approach-based on steady-state and strategic analysis-uses a few basic assumptions to construct a model that may be viewed as a representation of the international politics of the nineteenth century. The systems model discovers the mechanisms which maintain the system and the conditions under which it will tend to be maintained and those under which it will tend to be transformed. A brief description of the model of the loose bipolar system will indicate the way in which systems theory permits comparative analysis in international politics.

The loose bipolar international system also lacks a political subsystem. In this system, blocs as well as national actors participate. In addition, there are universal organizations like the United Nations and also uncommitted nations. The organization of this system can also be explained rather simply if one assumes that nations are predisposed toward maintaining their security. If, for any reason, two nations become predominant over the others in terms of capabilities, each will become the greatest potential danger to the other. In many matters, therefore-although not in all-they will be rivals and the natural foci of opposing alignments of nations. If, moreover, one bloc has rather permanent features, possibly because of supranational party connections, like those of the Communist party, it is important for other nations to form a relatively permanent bloc organized according to considerations of long-term rather than short-term interest. Unless they do this, the organized bloc will have obvious bargaining advantages, inasmuch as it would be able to split the others on prac- tically every issue while maintaining a united front.

Under the conditions just described, bloc alignments would be rigid rather than loose and flexible. They would not change over time and according to issue. Consequently, the "balancing" which characterized the "balance-of-power" system would be absent. Since there would still be a need in the system for mediation whenever the blocs found themselves in rigidly opposed positions, this function would be filled by the universal organization and by the uncommitted nations. The loose bipolar system would therefore tend with some exceptions to be a role-differentiated system unlike the "balance-of-power" system in which any major nation could play any role. The behavior of the loose bipolar system would also tend to be somewhat more complicated than the "balance-of-power" system, and role differentiation would be a feature of the system. Bloc actors would tend to subordinate the interests of the universal actor to those of their bloc, although they would also attempt to subordinate the interests of the other bloc to those of the universal actor. Uncommitted states, since their safety would largely depend on the universality of rules, would attempt to subordinate the interests of both blocs to those of the universal actor.

These models need not be portrayed at greater length here, and, in any event, they are somewhat oversimplified. But they do have the merit of stating the behavioral characteristics of the system, the internal system conditions under which the behavior will be maintained or transformed and also the major external conditions which are likely to maintain or produce a transformation in the system. They thus do give rise to predictions and can, with some caution, be applied to the explanation of some historical events. 
The instability of the "balance-of-power" system after the Franco-Prussian War, for instance, can be explained in terms of the model. Because of public opinion, the national response of France after the loss of Alsace-Lorraine did not permit a FrenchGerman alliance in the succeeding period, and therefore the flexible alliance policy called for by the theory could not be implemented. This naturally led to rigid and opposed alignments centered on France and Germany. Since the possibility of flexible realignment after war was remote, the incentive to limit wars or to maintain the rules of war was no longer present.

One can also use the theory to analyze why the principle of collective security failed. Alliances focalized responsibility, but collective security brought about a system in which the nations which had an interest in opposing aggression nonetheless had an interest in shifting the responsibility elsewhere, so that, as a consequence, none took any action. The great difference at the time of the Korean War stemmed from the fact that, with only two great nations in the world in a loose bipolar system, the United States could not shift its responsibility elsewhere and hence was compelled to act. Once it acted, others could afford to join in.

Thus the operation of the models depends upon parameter values that cannot be deduced from the models, such as the national temper of France and the corresponding inflexibility in Germany that resulted from French hostility, but which must be measured independently. The models, however, do predict disequilibrium when the parameters take these inconsistent values, and this kind of prediction is also subject to empirical confirmation.

More powerful advances in the theory of international politics will probably be related to a more rigorous application of the theory of games. Unfortunately, the difficul- ties in this respect aro severe. The stochastic ${ }^{4}$ game model, which is the most appropriate model, has received only elementary treatment at the hands of the game theorists, and this treatment is not yet adequate for many of the most important problems of international politics.

The importance of the stochastic game for the theory of international politics stems from the fact that it permits the theorist to analyze changes through time of the international system and thus to find out whether pathways exist to stable states, that is, to a stable set of strategic actions. The stochastic game can be used to analyze the learning behavior of the players. Since, in the stochastic game, the value of a strategy will depend upon expectations concerning the probabilities with which an opponent will use the strategies available to him, each player can learn about the other from the interaction process, and each can bargain and use threats or inducements to influence the behavior of the others. Will such patterns of behavior cycle without ever reaching equilibrium? Will they reach stable or unstable or desirable or undesirable equilibria? All these questions involve stochastic processes. Unfortunately, existing stochastic game models are not adequate for rigorous analysis of this sort, and very real theoretical difficulties stand in the way of rigorous analysis. If a theory of coalitions were devised and combined with adequate stochastic models, an important theoretical advance

4 A stochastic game, as that term is applied in Kaplan (3), chap. xi, refers to a game in which each player selects his strategies at each move on the basis of his expectations concerning the probabilities with which the other player will choose each of his strategies in response to any of the first player's strategy choices. Thus there is a complex interaction between the players in which expectations concerming the future help to determine the shape of the future. 
would be made. If such a theory were also combined with a theory concerning the cost and efficiency with which resources could be employed, a more inclusive theory of international politics would be in prospect.

Game theory is at that tantalizing stage of development at which its importance for the theory of international politics is clear, while, at the same time, it cannot be applied with rigor. At best, it appears that we can apply some aspects of the stochastic models to deductive models of international politics in a practical, rather than fully theoretical, manner. If, however, the theory of games can be applied with success in the construction of a theory of international politics, many of the unsettled questions, like the difference between Burns (2) and myself over whether the "balance-of-power" system has an inherent tendency to maintain or to reduce the number of major nations, will become susceptible to decision. Problems of coalition in simple alliances and in blocs should become susceptible to more precise analysis. Moreover, it should become possible to derive other unexpected consequences from the more rigorous theory and to subject the theory to test in a manner not presently possible.

\section{Some Broader Problems of Theory Construction}

\section{THEORY IN PHYSICAL SCIENCE}

There are some general problems of theory construction that are best explored by reference to physical science because the theoretical structure of the physical sciences is better developed than that of the social sciences and these problems have therefore been treated more precisely and explicitly in physical science. These problems concern the number of variables included in theories, the level of abstractness of theo- ries, and the relationship between theory and engineering applications of theories. A brief and general discussion of this problem will be useful in clarifying the relationship between Wright's work and the kind of theoretical structure for international politics that has just been proposed.

The term "theory" is not used in physical science as loosely as it is used in social science. Thus a scientist would not regard "doctors tend to have high income" or "Congressmen tend to mirror the views of their constituents" or "power is an important factor in international politics" as examples of theories. They would be regarded as formulas (or laws if they are universally true) which assert that two variables are enpirically correlated.

Formulas are used by physical science but usually within the framework of a theory which employs definitions and operations in addition to the formulas. This permits a rich interlinking of the formulas and provides an explanation of observed phenomena because the same terms are employed in many of the formulas and because the same operations are used in the employment of the terms. In this manner, science comprehends its data within a relatively simple explanatory theoretical structure within which the formulas acquire great power.

Generally where this kind of interlinking among formulas-or, even better, among theories-occurs, there is a reinforcement which makes the entire body of knowledge more probable than the individual propositions within it. Even where theory only produces propositions that are already' known, it adds to knowledge by uncovering the relationships between the propositions and by making clear the assumptions which bring the propositions within a unified framework. At its most powerful, however, theory leads to new predictions which 
would not have been made in its absence and to the expansion of the range and power of knowledge.

Physics has not been successful in deducing all physical knowledge from theories. This does not refer simply to the fact that at the present time mechanics and quantum theory cannot be treated within the same theoretical framework. It refers rather to the fact that not all observable phenomena can be given a theoretical explanation in practice and perhaps in principle.

Some impediments to theoretical development in physics stem from the choice of problems with large numbers of variables with relatively equal importance or from examining the wrong variables or from choosing the wrong parameters. One may examine situations in physical science either where theory is still weak or where the impediments to theory have been overcome to shed some light on the general problem. For instance, consider the situation in nuclear mechanics where a theory for the mechanics of nuclear particles has not yet been produced. Science, nonetheless, has many formulas and techniques for dealing with nuclear phenomena just as social science has many formulas for parts of the social process. As yet, one cannot be certain what the exact difficulties to theory construction are in this case. It may be that scientists have not produced a theory of nuclear mechanics because they have been using the wrong parameters, or it may be that nuclear phenomena are not amenable to theoretical treatment. The trouble may arise from the number of particles which have to be related. Even in macroscopic mechanics the physical scientist runs into enormous computational difficulties when he deals with many variables of relatively equal importance. Even where the variables are of the same kind but the number is large-for in- stance, four-body problems-the practical difficulties are great.

The physicist has a number of alternatives in cases with a large number of variables. And here the history of physics does provide us with a definite lesson. Perhaps the most economical alternative for the physicist is to change the problem by satisfying himself with less information. The statistical treatment of gas particles adopts this solution. The attempt is made to predict the general behavior of the gas rather than the specific behavior of the individual particles. Other problems that resist theoretical treatment may be solved if one finds the right dependent variables. The ancient physicists or philosophers, when attempting to deal with the motion of bodies, tried to account for the whole movement. They assumed that the straight line and the perfect circle were the only natural forms and attempted to account for all other motions as deviations from these forms. It was only when Galileo decided modestly that he would be satisfied with predicting the path of an object from a given position and momentum, that the powerful development of modern physics was freed from its classic chains. Thus the physicist must compromise again and again and settle for less predictive power than he originally intended.

There are occasions, such as designing planes or building bridges, where the engineer needs more information than the physicist can give him. In such circumstances, he may resort to several devices. The engineer may employ trial-and-error experimentation, or he may act on the basis of past experience just as the ancient astronomer plotted the paths of the heavenly bodies in order to make his predictions. Such methods are useful, but they lack the cumulative power of theoretical science. The engineer can also use the basic laws of physics by estimating and fitting parameters and then 
by making step-by-step estimates of the ways in which a large number of variables fit together, making use of some observational knowledge in the process. Thus we know that physics cannot deal theoretically with very complex problems, that the theoretical problem must be simplified and engineering applications employed when our practical needs are not satisfied by the direct derivations from theory.

\section{THEORY AND ENGINEERING IN}

\section{INTERNATIONAL POLITICS}

We have come a long way from our starting point and little direct attention has been given to The Study of International Relations. This does not reflect a lack of concern with Wright's important work but rather an effort to elucidate its relationship to a theory of international politics. Wright's work cannot serve as the core of a theory of international politics for three major reasons: (1) its scope is so extensive and the number of disciplines it treats so large that no workable unified theory can emerge; (2) it does not account for rational strategic behavior that plays so large a role in international politics; and (3) it does not explore the comparative structure of the international system. These remarks are not made critically, however, for Wright never claimed to have provided a theory in the sense used here. Rather, he claimed that his approach permitted the study of international relations. This is a claim that deserves serious consideration, and the preceding sections of this article help to understand and to establish that claim.

In order to develop a theory of international politics, the number of variables must be reduced to a minimum, as was explained above. This means that the theory will have nothing to say about specific intemational situations. There will be a definite gap between the theory and its application,
Theory can tell us, for instance, that the maintenance of the bloc system is essential to the stability of the loose bipolar sy-stem. There is a gap between this assertion and the formulation of an American policy for North Africa. What will be the consequences for NATO of alternative policies? Possibly a pro-Algerian decision would lead to the withdrawal of France from NATO. But there may still be special considerations with respect to the maintenance of African bases which counterbalance this. Moreover. French withdrawal from NATO if the United States pursues a pro-Algerian policy is not certain. Indeed, if France is permitted to persist in its present policy, there is at least some possibility that the resulting political upheaval in France. Algeria, and Tunisia may led to the withdrawal of both France and North Africa from co-operation with the United States. We have just begun to indicate the complexities of the problem, but surely this already indicates the extent to which a theory of international politics camnot guide us in our practical decisions. This does not mean that a theory of international politics is unimportant. The theory of international politics sets constraints upon the problem which it is essential for the decision-maker to understand. But a theory of international politics is not sufficient.

If one wants to make individual predictions, it is necessary to fit the parameters of the basic formulas of the theory of international politics and then to make step-bystep estimates on the basis of an understanding of the ways in which social, psychological, economic, and legal variables, etc., affect the actions of nations. Wright's work is of major importance in moving from the abstract theory of intemational politics to the real world of international activities. The field analysis which Wright developed permits the expert to use all the social science disciplines in order to determine how 
national activity will be modified by the parameters of the international process at any step in the complicated interaction process.

Wright's field analysis is an important theoretical contribution to the study of international relations, but it does not constitute a theory of international politics. There is no theory of the structure or process of the international political system, nor is there any way, unless Wright's work is supplemented by a basic theory of international politics, to estimate the consequences of conforming or deviant behavior to the stability of the system of international behavior. One cannot use mechanical formulas to analyze the behavior of nations as they learn to deal with different types of behavior by other players and to adopt forms of behavior which are oriented toward maintaining a set of social rules. It is true, for instance, that some policies may develop as a consequence of hysteria and that these policies can be analyzed best in terms of mechanical causation. But the general pattern of international behavior and its stability can be analyzed best in terms of strategic considerations. The parameter values that inhibit rationality function in much the same way as does the air friction which slows down the path of a moving body. The central theory of international politics from which the deviations are measured, however, must be the pattern of rational strategic interaction, just as physics uses the frictionless path as one of its key concepts.

Wright's work is therefore of primary use in fitting parameters. It enables us to carry out the engineering task of deciding individual cases by providing us with criteria for selecting the relevant variables which individualize national behavior. We may quibble over whether international economics is always the appropriate branch of eco- nomics with respect to individual cases. But Wright provides a theoretical framework within which parameters can be fitted. And a theoretical framework for the parameters is of urgent practical importance, even though it does not constitute a theory of international politics.

One may hope that some simplification of Wright's categories may prove possible. Alternatively, one may employ quite different kinds of theoretical models to help in predicting the values that the parameters might take. For instance, one might employ organizational typologies and models. ${ }^{5}$ But the considerations to which Professor Wright's Study of International Relations directs our attention are of decisive importance, and the range of variables he includes within his action space model is impressive.

Thus there are two basic approaches: one concerned with a macroscopic theory of international politics and the other concerned with estimating parameters. These approaches, properly understood, complement and supplement each other. The macroscopic theory of international politics must remain academic if it never can be applied, although it may still be possible to obtain some heuristic insights from it. The method of Professor Wright, on the other hand, has great importance in estimating how nations will behave but will not give much help in evaluating the consequences of particular decisions upon the future stability and behavior of the international system.

\section{REFERE N C E S}

1. Ashry, W. Ross. Design for a Brain. Now York: John Wiley \& Sons, 1952.

2. Bunns, Aktuun L. "From Balance to De-

5 I attempted to do this in part in chap. iii and also in Part II of System and Process in International Politics. 
terrence," World Politics, IX, No. 4 (1957), 494-529.

3. Kaplan, Morton A. System and Process in International Politics. New York: John Wiley \& Sons, 1957.

4. Lasswell, Harold. Analysis of Political Behavior. New York: Oxford University Press, 1947.

5. -- . World Politics and Personal Insecurity. New York: McGraw-Hill Book Co., 1935.

6. Levy, Marion J. The Structure of Society. Princeton: Princeton University Press, 1952.
7. Luce, Duncan, and Raiffa, Howard. Games and Decisions. New York: John Wiley \& Sons, 1957.

8. Parsons, Talcott. The Social System. Glencoe: Free Press, 1951.

9. Von Neumann, John, and Morgenstern, Oscar. The Theory of Games and Economic Behavior. Princeton: Princeton University Press, 1944.

10. Wright, Quincy. The Study of International Relations. New York: Appleton-Century-Crofts, 1955.

11. _-_. A Study of War. Chicago: University of Chicago Press, 1942. 